Review article

\title{
Real-world experience with ombitasvir/paritaprevir boosted with ritonavir and possibly combined with dasabuvir and ribavirin in HCV infection
}

\author{
Joanna Pogorzelska, Robert Flisiak \\ Department of Infectious Diseases and Hepatology, Medical University of Bialystok, Poland
}

\begin{abstract}
Ombitasvir/paritaprevir boosted with ritonavir and possibly combined with dasabuvir and ribavirin (OBV/PTV/r $\pm \mathrm{DSV} \pm \mathrm{RBV}$ ) is a new direct-acting antiviral (DAA) regimen which has improved efficacy of chronic hepatitis $C$ virus $(\mathrm{HCV})$ treatment significantly. OBV/PTV/ $\mathrm{r} \pm \mathrm{DSV} \pm \mathrm{RBV}$ in clinical trials demonstrated sustained viral response (SVR) rates close to $100 \%$. In this article we collected currently available data of 5726 patients for evaluation of OBV/PTV/r \pm DSV \pm RBV efficacy and safety in real-world experience. The sustained viral response rate in this large population was $97 \%$, and it was exactly the same even in patients with liver cirrhotics. According to this meta-analysis, less than $3 \%$ of patients discontinued treatment due to adverse events.
\end{abstract}

Key words: HCV, paritaprevir, ombitasvir, dasabuvir.

Address for correspondence

Joanna Pogorzelska, Department of Infectious Diseases and Hepatology, Medical University of Białystok, 14 Żurawia St., 15-540 Białystok, Poland, e-mail: pogorzelska.joanna@gmail.com

\section{Introduction}

Direct-acting antiviral (DAA) regimens improved the efficacy of chronic hepatitis $\mathrm{C}$ virus (HCV) treatment. Ombitasvir, paritaprevir boosted with ritonavir and possibly combined with dasabuvir and ribavirin $(\mathrm{OBV} / \mathrm{PTV} / \mathrm{r} \pm \mathrm{DSV} \pm \mathrm{RBV})$ were licensed in the European Union in 2014 for use as a combination therapy for $\mathrm{HCV}$ infection $[1,2]$. OBV/PTV/r $\pm \mathrm{DSV} \pm \mathrm{RBV}$ became reimbursed in Poland for patients infected with genotype 1 and 4, irrespectively of fibrosis or previous treatment history starting from July 2015 as the first available interferon-free regimen and included in clinical practice guidelines issued by the Polish Group of HCV Experts [3]. However, early access to these innovative medications has been provided since November 2014, mostly for patients with advanced liver fibrosis, who were included in the AMBER real world study [4-6]. Similar real-world studies were carried out in numerous countries and preliminary results became available during the European Association for the Study of the Liver (EASL) International Liver Congress in Barcelona in April 2016 (ILC-EASL 2016). In this article we have collected currently available data on the efficacy and safety of OBV $/ \mathrm{PTV} / \mathrm{r} \pm \mathrm{DSV} \pm \mathrm{RBV}$ in realworld practice, which have been presented recently.

\section{Characteristics of the regimen}

The three DAA - ombitasvir (OBV), paritaprevir (PTV) and dasabuvir (DSV) - are formulated into two tablets and manufactured by AbbVie. Viekirax, which contains $12.5 \mathrm{mg}$ of OBV plus $75 \mathrm{mg}$ of PTV boosted with $50 \mathrm{mg}$ of ritonavir $(\mathrm{OBV} / \mathrm{PTV} / \mathrm{r}$ ) and Exviera, consists of $250 \mathrm{mg}$ of DSV as sodium monohydrate. According to the products' characteristics, OBV/PTV/r \pm $\mathrm{DSV} \pm \mathrm{RBV}$ are dedicated for the treatment of chronic hepatitis $C$ in adults infected with genotype (GT) 1 and $4[7,8]$. Therapy for genotype $1 \mathrm{a}$ and $1 \mathrm{~b}$ is based on a fixed-dose regimen that includes OBV/PTV/r taken as 2 tablets once daily, and DSV in the second tablet taken twice a day. OBV/PTV/r without DSV is used for treatment of patients infected with GT4. The addition of a weight-adjusted dose of RBV is required in all patients 
infected with genotype 1a and $4 \mathrm{HCV}$. According to the most recent label, RBV is not required in patients infected with genotype $1 \mathrm{~b}$, which is predominant in Central Europe. The standard duration of therapy is 12 weeks for GT1b infection without cirrhosis and with compensated cirrhosis. Patients infected with GT1a without cirrhosis should be treated in combination with RBV for 12 weeks, and in the case of those with compensated cirrhosis treatment should be extended to 24 weeks.

$\mathrm{OBV} / \mathrm{PTV} / \mathrm{r} \pm \mathrm{DSV}$ therapy should not be used in patients with advanced liver failure and a Child-Pugh score of C. Patients with a history of hepatic decompensation including patients with a Child-Pugh score of $\mathrm{B}$ can be considered for treatment under close monitoring in experienced hepatologic centers [3].

\section{Real-world experience}

Phase 3 clinical trials carried out with OBV/PTV/r $\pm \mathrm{DSV} \pm \mathrm{RBV}$ have shown SVR rates exceeding $90 \%$, irrespective of genotype, liver fibrosis or previous history of treatment [9]. Real-world data usually provide efficacy lower compared to clinical trials because they include more divergent and non-adherent populations. In a number of real world studies presented in Table $1, \mathrm{OBV} / \mathrm{PTV} / \mathrm{r} \pm \mathrm{DSV} \pm \mathrm{RBV}$ based treatment was effective as it was demonstrated in clinical trials and achieved high rates of SVR12 in the range of 91$100 \%$, irrespective of liver fibrosis, previous history of treatment or genotype. As shown in Table 2 this regimen was well tolerated in adults and was associated with low rates of treatment discontinuation.

The first interim analysis carried out in the AMBER study was presented during the Viral Hepatitis Congress in Frankfurt in 2015 and demonstrated a fast virologic response, similar to that observed in registration studies [4]. Final data also confirmed the SVR12 rate of $99 \%$ in a population of 209 patients consisting mostly of GT1b infected, cirrhotics and non-responders to previous therapy, including failures of triple

Table 1. Overview of efficacy in real-world studies with OBV/PTV/r \pm DSV \pm RBV in HCV infection

\begin{tabular}{|c|c|c|c|c|c|c|}
\hline Reference & Country & $\begin{array}{c}\text { Number of } \\
\text { patients } \\
n\end{array}$ & $\begin{array}{c}\text { Proportion of } \\
\text { known genotypes } \\
1 / 1 \mathrm{a} / 1 \mathrm{~b} / 4 \\
n\end{array}$ & $\begin{array}{c}\text { Cirrhosis } \\
n(\%)\end{array}$ & $\begin{array}{l}\text { SVR } 12 \text { in all } \\
\text { patients } \\
n(\%)\end{array}$ & $\begin{array}{c}\text { SVR } 12 \text { in } \\
\text { cirrhosis } \\
n(\%)\end{array}$ \\
\hline Aghemo [14] & Italy & 42 & & $42(100)$ & $41(98)$ & $41(98)$ \\
\hline Calleja [11] & Spain & 1422 & $8 / 247 / 1312 / 0$ & $732(47)$ & $1376(97)$ & 710 (97) \\
\hline Christensen [15] & Germany & 87 & & & $83(95)$ & \\
\hline Derbala [16] & Qatar & 42 & $0 / 0 / 0 / 42$ & $24(36)$ & $41(98)$ & $24(100)$ \\
\hline Flisiak [6] & Poland & 209 & $11 / 13 / 176 / 9$ & $119(57)$ & 207 (99) & $117(98)$ \\
\hline Gomez [17] & Spain & 31 & & & $31(100)$ & \\
\hline Hinrichsen [18] & Germany & 558 & $0 / 141 / 351 / 53$ & $127(24)$ & $539(97)$ & $129(95)$ \\
\hline Hunyady [13] & Hungary & 61 & $61 / 0 / 0 / 0$ & & $60(98)$ & \\
\hline Jeruma [19] & Latvia & 15 & $0 / 0 / 15 / 0$ & $15(100)$ & $15(100)$ & $15(100)$ \\
\hline Londono [20] & Spain & 37 & & & $36(97)$ & \\
\hline Lubel [21] & Australia & 167 & $167 / 0 / 0 / 0$ & & $167(92)$ & (91) \\
\hline Mateya [22] & Bulgaria & 62 & & & $61(98)$ & \\
\hline McCombs [12] & USA & 1012 & $773 / 0 / 0 / 0$ & $350(35)$ & $945(93)$ & $329(94)$ \\
\hline Ouzan [23] & France & 20 & $15 / 0 / 0 / 5$ & & $20(100)$ & \\
\hline Perello [24] & Spain & 77 & & & $75(97)$ & \\
\hline Petta [25] & Italy & 728 & & $728(100)$ & 712 (98) & 712 (98) \\
\hline Rincon [26] & Spain & 547 & & & $538(98)$ & \\
\hline Teti [27] & Italy & 193 & 193/0/0/0 & & $188(97)$ & \\
\hline Zuckerman [10] & Israel & 416 & $416 / 0 / 0 / 0$ & $253(62)$ & $413(99)$ & 251 (99) \\
\hline Overall & & 5726 & $\begin{array}{c}1644 / 401 / \\
1854 / 109\end{array}$ & $2390(54)$ & $5548(97)$ & $2328(97)$ \\
\hline
\end{tabular}


Table 2. Available safety data of OBV/PTV/r \pm DSV \pm RBV treatment in real-world experience

\begin{tabular}{lccc}
\hline Reference & $\begin{array}{c}\text { Patients discontinued due } \\
\text { to adverse events } \\
\boldsymbol{n}(\%)\end{array}$ & $\begin{array}{c}\text { Patients with hepatic } \\
\text { decompensation } \\
n(\%)\end{array}$ & $\begin{array}{c}\text { Serious adverse events } \\
n(\%)\end{array}$ \\
\hline Calleja [11] & $24(1.8)$ & $8(0.5)$ & $84(5.4)$ \\
\hline Flisiak [5, 6] & $5(2.4)$ & $7(3.3)$ & $8(3.8)$ \\
\hline Hinrichsen [18] & $8(3)$ & 0 & $13(2)$ \\
\hline Hunyady [13] & 0 & 0 & $3(3.8)$ \\
\hline Lubel [21] & $3(1.1)$ & $6(2.2)$ & $9(3.4)$ \\
\hline Zuckerman [10] & $20(3)$ & $8(1.2)$ & $25(3.8)$ \\
\hline
\end{tabular}

regimens [6]. Serious adverse events (SAEs) were observed in 8 patients $(3.8 \%)$, and 5 patients $(2.4 \%)$ discontinued treatment due to adverse events (AE). Risk of on-treatment decompensation was associated with a history of decompensation before the treatment and baseline hepatic function [5]. Adverse events were observed in 151 patients (72\%), and they were mostly related to RBV [6]. Almost exactly the same efficacy (SVR rate 99\%) and safety results were achieved by Zuckerman et al. [10] in a population of mostly cirrhotic Israeli patients infected with genotype 1 (subgenotyping not available).

The highest number of enrolled patients was in the multicenter Spanish study presented at the ILC-EASL 2016 by Calleja et al. [11]. The analysis covered 1422 GT1 (mostly GT1b) infected patients; $49 \%$ of them were treatment experienced, and $47 \%$ were cirrhotics. The SVR12 rate in this population was $97 \%$. In a multivariate analysis, a decreased probability of achieving SVR was associated with low baseline albumin. No statistical differences were associated with genotype, age or stage of fibrosis. Serious adverse events occurred in 84 patients $(5.4 \%)$ and $1.8 \%$ discontinued early. The most frequent SAE was anemia, associated with RBV (24 patients, 1.5\%), skin lesions (11 patients, $0.7 \%$ ) and infections ( 8 patients, $0.5 \%$ ). Occurrence of SAEs was related to MELD score, high transient elastography values and advanced age.

Another large real world study was presented by McCombs et al. [12] from the United States Veterans Health Administration. They carried out an analysis of 1012 patients infected mostly with GT1 (76\%), 1/3 with liver cirrhosis, and the final efficacy rate was $93 \%$. In this study HBV and HIV coinfections, as well as diabetes and obesity, were found to have no statistically significant impact on the likelihood of achieving SVR 12.

In a relatively small but important study Hunyady et al. [13] demonstrated that failure of the interferon-based triple regimen containing the first generation protease inhibitor boceprevir or telaprevir did not affect the high efficacy of OBV/PTV/r \pm DSV $\pm \mathrm{RBV}$ (SVR rate $98 \%$ ).

Treatment of 5726 patients, including 2390 cirrhotics, with OBV/PTV/r \pm DSV $\pm \mathrm{RBV}$ in real-word studies with currently available data was safe and therapeutic success was achieved by 5548 patients, so the SVR rate calculated in this metaanalysis was $97 \%$ in both the general population and in patients with liver cirrhosis (Table 1). The discontinuation rate due to $\mathrm{AE}$ did not exceed $3 \%$, and SAEs were observed in $2-5.4 \%$ of patients (Table 2). Anemia and hyperbilirubinemia occurred usually in cirrhotics receiving RBV [21]. However, due to the exclusion of RBV from the regimen for GT1b patients, according to the most recent label, this problem should disappear in a large majority of European patients.

According to results of randomized clinical trials, the $\mathrm{OBV} / \mathrm{PTV} / \mathrm{r} \pm \mathrm{DSV} \pm \mathrm{RBV}$ regimen has been found to fulfill the promise of SVR rates close to $100 \%$. However, the most important requirement is confirmation of such high efficacy in real-world experience in the large, mixed population of patients previously considered as "difficult to treat".

\section{Disclosure}

The authors report no conflict of interest.

\section{References}

1. European Association for Study of Liver. EASL recommendations on treatment of hepatitis C 2015. J Hepatol 2015; 63: 199-236.

2. Flisiak R, Urbánek P, Rokusz L, et al. New therapeutic options for HCV in Central Europe. Clin Exp Hepatol 2016; 1: 7-11.

3. Halota W, Flisiak R, Boroń-Kaczmarska A, et al.; Polish Group of HCV Experts. Recommendations for the treatment of hepatitis C Polish Group of HCV Experts - 2015. Clin Exp Hepatol 2015; 3: 97-104.

4. Flisiak R, Janczewska E, Wawrzynowicz-Syczewska M, et al. Efficacy and safety of paritaprevir/r/ombitasvir/dasabuvir \pm ribavirin in genotype $1 \mathrm{HCV}$ infected patients treated in real life settings (AMBER study). J Viral Hepatitis 2015; 22 (Suppl 3): 4. 
5. Flisiak R, Jaroszewicz J, Janczewska E, et al. Predictors of decompensation during ombitasvir/paritaprevir/ritonavir \pm dasabuvir \pm ribavirin treatment of genotype 1 and $4 \mathrm{HCV}$ infected patients (real life AMBER study). J Hepatol 2016; 64 (Suppl 2): SAT-253.

6. Flisiak R, Janczewska E, Wawrzynowicz-Syczewska M, et al. Realworld efficacy and safety of ombitasvir/paritaprevir/ritonavir \pm dasabuvir \pm ribavirin in HCV infection: AMBER study. Hepatology 2016, submitted for publication.

7. Viekirax, Charakterystyka Produktu Leczniczego.

8. Exviera, Charakterystyka Produktu Leczniczego.

9. Łucejko M, Parfieniuk-Kowerda A, Flisiak R. Ombitasvir/paritaprevir/ritonavir plus dasabuvir combination in the treatment of chronic HCV infection. Expert Opin Pharmacother 2016 [In press]; available on-line: http://dx.doi.org/10.1080/14656566.20 16.1176143 .

10. Zuckerman E. The real-world Israeli experience treating chronic hepatitis $\mathrm{C}$, genotype 1 patients with advanced fibrosis with paritaprevir/ritonavir/ombitasvir, dasabuvir with or without ribavirin: a large multi-center cohort. J Hepatol 2016; 64 (Suppl 2): PS004.

11. Calleja J, Rincon D, Ruiz-Antoran B, et al. Effectiveness and safety of ombitasvir and paritaprevir, ritonavir and dasabuvir patients with genotype 1 chronic hepatitis $\mathrm{C}$ virus infection: results from Spanish real world cohort. J Hepatol 2016; 64 (Suppl 2): LBP-512.

12. McCombs J, Mc Ginnis J, Fox S, et al. Analysis of the real world effectiveness of direct acting antivirals treatments of hepatitis $C$ in a Large Population. J Hepatol 2016; 64 (Suppl 2): LBP-510.

13. Hunyady B, Abonyi M, Gervain J, et al. Ombitasvir/Paritaprevir/Ritonavir + Dasabuvir + Rybaviryn (3D+Rybaviryn) treatment of hepatitis C (HCV) genotype 1 (GT1) infected patients (pts) after failure to previous first generation protease- inhibitor (PI) therapy. Interim analysis. J Hepatol 2016; 64 (Suppl 2): SAT- 120.

14. Aghemo A, Cologni G, Maggiolo F, et al. Safety and efficacy of directly acting antivirals in $2432 \mathrm{HCV}$ patients with advanced fibrosis: an interim analysis of the Lombardia Regional Network for Viral Hepatitis. J Hepatol 2016; 64 (Suppl 2): LBP-500.

15. Christensen S, Ingiliz P, Schewe K, et al. Relapse and treatmentermergent ravs with DAA-based regiments in hepatitis $C$ virus infection (HCV) mono-or-human immunodeficiency virus (HIV)-HCV Co-infected patients - a real concern in clinical practice? Results from the German hepatitis C cohort (GECCO). J Hepatol 2016; 64 (Suppl 2): STA-265.

16. Derbala M, Amer A, Alkaabi S, et al. Efficacy and safety of Ombitasvir/Paritaprevir/Ritonavir, with or without Ribavirin, in patients with HCV genotype 4 infection- real- world experience from Qatar. J Hepatol 2016; 64 (Suppl 2): SAT-220.

17. Gomez R, Rincon D, Hernandez E, et al. Ombitasvir/Paritaprevir/Ritonavir plus Dasabuvir are safety and efficacy for treating HCV GT1 and GT 4 infection in patients with severe renal impairment or end stage renal disease: a multicenter experience. J Hepatol 2016; 64 (Suppl 2): SAT-248.

18. Hinrichsen H. Real-world safety and effectiveness of Ombitasvir/Paritaprevir with Dasabuvir and/or Ribavirin in the German Hepatitis C Registry. J Hepatol 2016; 64 (Suppl 2): GS07.

19. Jeruma A, Tolmane I, Rosentale B. 100\% efficacy of hepatitis C treatment in cirrhotic patients: real life results in Latvia. APASL 2016. Poster presentation.

20. Londono MC, et al. $41^{\text {st }}$ Congreso Annual AEEH 2016. Oral presentation.
21. Lubel JS, Pianko S, Strasser T, et al. Real world evaluation of Viekira Pak (Ritonavir Boosted Paritaprevir, Ombitasvir and Dasabuvir \pm Ribavirin) in HCV genotype 1 targeting advanced liver disease (The Revltal Study). J Hepatol 2016; 64 (Suppl 2): SAT- 182.

22. Mateya L, Antonov K. National Hepatology Conference. Bulgaria 2015.

23. Ouzan D, Penaranda G, Delasalle ChR, et al. Avdlib 2: News Direct - acting antiviral (DDA) in $\mathrm{HCV}$ patients with advanced liver disease. Final results of a the second multicenter prospective observational study in real life practice in France. J Hepatol 2016; 64 (Suppl 2): THU-218.

24. Perello C, et al. $41^{\text {st }}$ Congreso Annual AEEH 2016. Poster \#95.

25. Petta S. AISF Annual Meeting 2016.

26. Rincon D, et al. $41^{\text {st }}$ Congreso Annual AEEH 2016. Oral presentation.

27. Teti S, Ricciardi A, Antinori A, et al. Dasabuvir and Ombitasvir/Paritaprevir/Ritonavir with or without Ribavirin in patients with HIV-HCV coinfection: real life interim analysis of an Italian multicentre compassionate use program. J Hepatol 2016; 64 (Suppl 2): SAT-147. 
